\title{
Biosafety bungle leads to bird flu contamination
}

In February, a group of experimental ferrets at a research facility in the Czech Republic fell ill. The ferrets had recently been injected with a culture containing what was believed to be a straight shot of the seasonal influenza virus, but their symptoms were severe and wholly unexpected. Researchers later determined that they were suffering from avian influenza; the seasonal flu culture had been contaminated with the deadly virus $\mathrm{H} 5 \mathrm{~N} 1$.

The flu sample, which came from an Austrian laboratory owned by Baxter International, ended up in at least three other labs in Austria, Germany and Slovenia. Although no one has fallen ill as a result of the mix-up, experts say the incident raises biosafety concerns and highlights the need for better quality control.

"I think it points to major problems," says David Topham, a microbiologist at the University of Rochester Medical Center and co-director of the New York Influenza Center of Excellence. Although contamination can happen easily, he says, there should be sufficient safety measures in place to prevent it.

Christopher Bona, a spokesperson for the Illinois-based Baxter, says it is "highly unlikely" that anyone was exposed to the avian flu virus. $\mathrm{He}$ adds that the contamination was due to "a combination of process, technical and human error," but that the problem has since been corrected. Bona refused to give specific details about how the accident occurred, noting that Baxter's processes are proprietary.

Although the World Health Organization and the European Centre for Disease Prevention and Control are aware of the incident, the Austrian Ministry of Health has jurisdiction over Baxter's lab in OrthDonau. The ministry audited the lab after the accident. "Nothing alarming was found," says Sigrid Rosenberger, a spokesperson for the ministry.

Baxter's Austrian lab had sent the flu culture to the Vienna-based Avir Green Hills Biotechnology, which is developing a live attenuated influenza vaccine. Avir workers handled the contaminated material in Vienna, but they also sent the culture to three subcontractors, including the facility in the Czech Republic. Topham says employees working at these labs would have had the greatest risk of contracting avian influenza. But, he adds, the risk is minimal unless the virus is introduced directly into the respiratory tract, a situation that would be unlikely if the lab workers followed standard biosafety procedures.
According to Avir, all potentially exposed employees have been examined and treated with antiviral medicines. Furthermore, the contaminated product has been destroyed, and all of the labs have been sanitized. "At no time was there any danger to the population or the environment," says Birgit KoflerBettschart, a spokesperson for the company.

Still, the incident has left many concerned. It highlights "a potential hole in the regulation of the early stages of vaccine research," says Gregory Härtl, a spokesperson at the World Health Organization.
"The mere fact that this could happen," says Albert Osterhaus, head of the virology department at Erasmus University Medical Center in Rotterdam, "indicates that there is something wrong." Osterhaus would like to see Baxter help others learn from its mistake: "when you see [...] holes in the system, I think it's important to share that with the people that are working in this particular area." It's like the aftermath of a plane crash, he says. "It's always very important to see what went wrong."

Cassandra Willyard, New York

\section{Blueprint for autism research put forward}

After a year of gathering input from top scientists and vocal public advocates, a US federal government advisory panel has released a blueprint of priorities for autism research.

The 'strategic plan', mandated by the Combating Autism Act in December 2006 and completed on 26 January of this year, recommends 40 specific projects to study the diagnosis, cause and lifelong care of the developmental disorder, which, by some estimates, affects one in 150 people.

The plan, made public on 5 March, estimates the combined cost of implementing short-term and long-term research priorities for autism at nearly $\$ 800$ million-but has no authority to appropriate federal money.

"It's not actually dictating to anybody

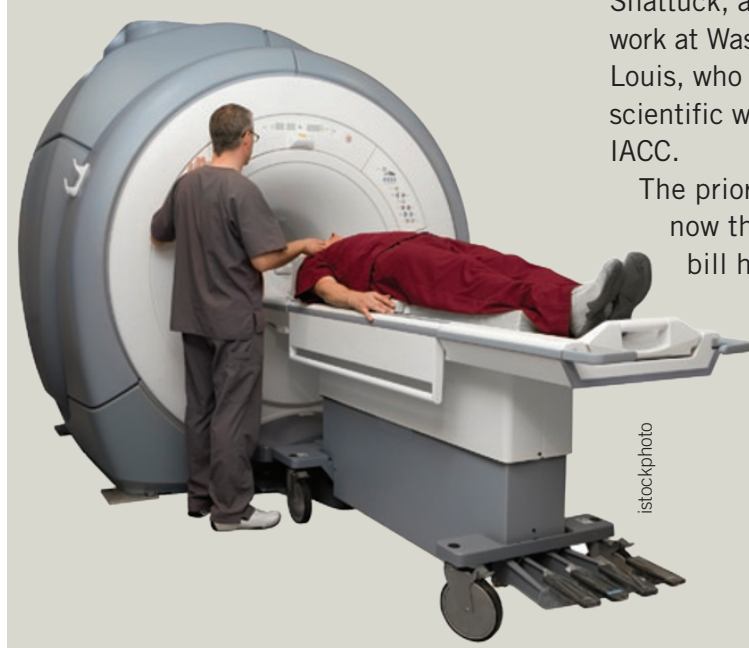

Autism clues: Brain scans have offered insights about what research must be funded," says Tom Insel, director of the US National Institute of Mental Health and chair of the Interagency Autism Coordinating Committee (IACC), which wrote the plan. "Our hope is that now that this document is available, the various agencies will be able to use this to help set priorities for funding in autism."

The plan emphasizes underfunded areas of research, particularly biomedical treatments and environmental risk factors, Insel adds.

Although autism scientists are generally optimistic about the plan, some take issue with its skewed focus on childhood.

"Pretty much all the money [in autism research] has gone into early childhood etiology. We know very little about what happens in adulthood," says Paul Shattuck, assistant professor of social work at Washington University in St. Louis, who participated in one of the workshops organized by the

The priorities may be especially useful now that the economic stimulus bill has passed: the $\$ 8.2$ billion it allocated to the US National Institutes of Health (NIH) for research must be spent by 2010 . Of that money, the NIH has set aside $\$ 200$ million to fund at least 200 'Challenge' grants, one of which calls for carrying out studies in the IACC's plan.

Virginia Hughes, New York 